\title{
NO $_{\mathrm{x}}$ Data Processing
}

The EcoPhysics chemiluminescence instrument was delivered after a Swiss factory calibration/certification on 5/28/2015. Later that summer, after integration onto the aircraft, California Air Resources Board's (CARB) Mobile Quality Assurance $\mathrm{Lab}$ conducted an audit on 7/21/2015 of the aircraft measurements of $\mathrm{O}_{3}, \mathrm{NO}, \mathrm{NO}_{2}$, and temperature. Since we did not set up

5 the lamp cycling software, lamp efficiency correction, and because there was an unexpected offset coming from the lamp, the NO2 measurement failed the audit. After several more days of "burn-off" and testing the NOx measurements were improved and a return audit of by CARB's Mobile Lab on 8/6/2015 was successful (ARB Audit \#: 57997). In between deployments we performed our own calibrations of the $\mathrm{NO}_{x}$ system via ozone titration of a NIST-certified NO cylinder (typically 100 ppbv) and zero-air dilution. The average slope of all the calibrations was found to be $1.005( \pm 0.026)$ and the average offset was 1.1

$10 \mathrm{ppb}( \pm 0.4 \mathrm{ppb})$ (see Figure 1 for an example calibration). Each deployment data set was corrected for the average coefficients of the calibrations performed before and after the deployment.

\section{Exponential Correction}

Analysis of $\mathrm{NO}_{x}$ data from this field campaign revealed a trend of systematic decay in the $\mathrm{NO}_{2}$ signal for most flights. This trend was corrected in the final dataset. The following describes the laboratory testing that was done to characterize the decay

15 and remove it.

Data was logged for several hours with the lamp on, occasionally switching the lamp off for approximately 1 minute at a time to check the NO signal on multiple separate occasions. The decay signal observed in the airplane was replicated in the lab for all experiments. Since ambient air was being measured, it was assumed that laboratory values of $\mathrm{NO}$ and $\mathrm{NO}_{2}$ will remain fairly constant throughout the duration of each experiment. An exponential correction was then applied using the following 20 procedure:

(1) A time series is created for the species $\mathrm{C}$, where $\mathrm{C}$ is either $\mathrm{NO}$ or $\mathrm{NO}_{2}$.

(2) A median value, $\mathrm{X}$, is obtained for $\mathrm{C}$ where $\mathrm{t}>3600$ seconds.

(3) With $t$ on the $x$-axis and $\ln (C-X)$ on the $y$-axis, the linear regression $(m x+b)$ of the scatter plot is taken for all points where C-X $>0$.

25 (4) An exponential decay function of time is generated: $f(t)=e^{b} e^{m t}$

(5) The new time-series of $\mathrm{C}$, now corrected for the exponential decay, is generated as follows:

$$
C^{\prime}{ }_{t}=C_{t}-\left[f_{t}-f_{\text {tmax }}\right]
$$

Where $t_{\max }$ is the last time series point of the flight.

An example corrected time series can be seen in . 


\section{Altitude Correction}

Another artifact of the ecophysics is that the signal changes slightly as a function of altitude. In order to correct for this, we performed a calibration where $107 \mathrm{ppbv}$ of NO is delivered to the instrument. The results of this calibration leads to the following correction:

$$
N O_{(x)}=\frac{106.64-\left(0.0027 * z_{m M S L}\right)}{107}
$$

Where $Z_{\mathrm{m}}$ MSL is the altitude in meters above mean sea level. 


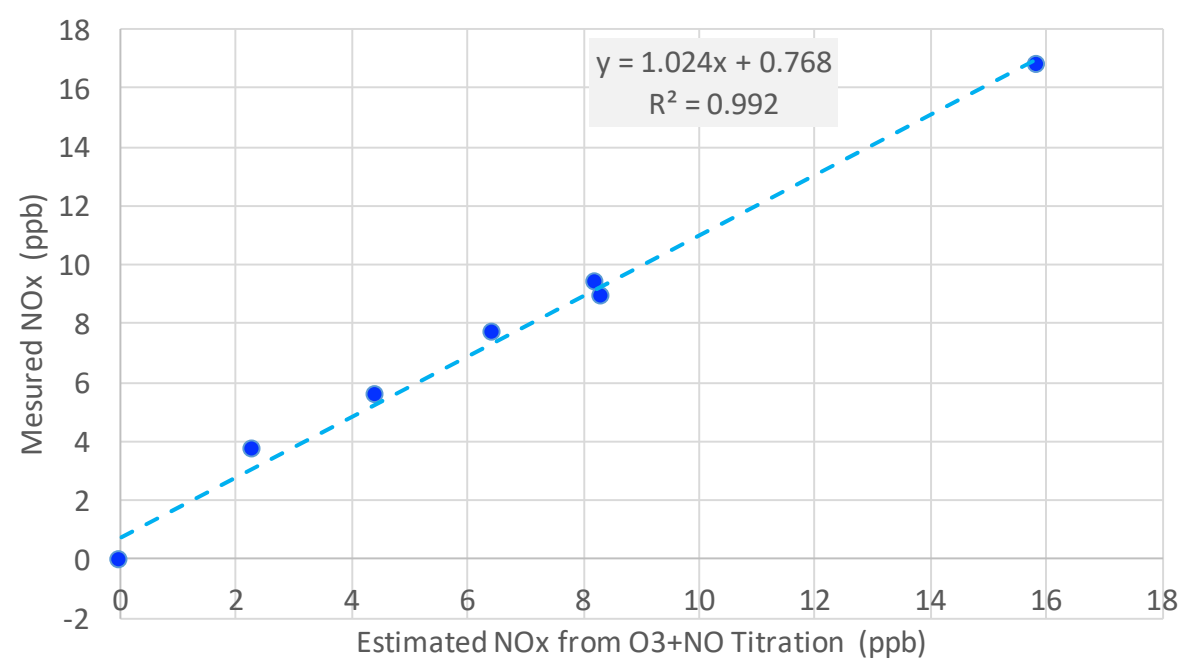

Figure 1 EcoPhysics NOx calibration from July 26, 2016. 


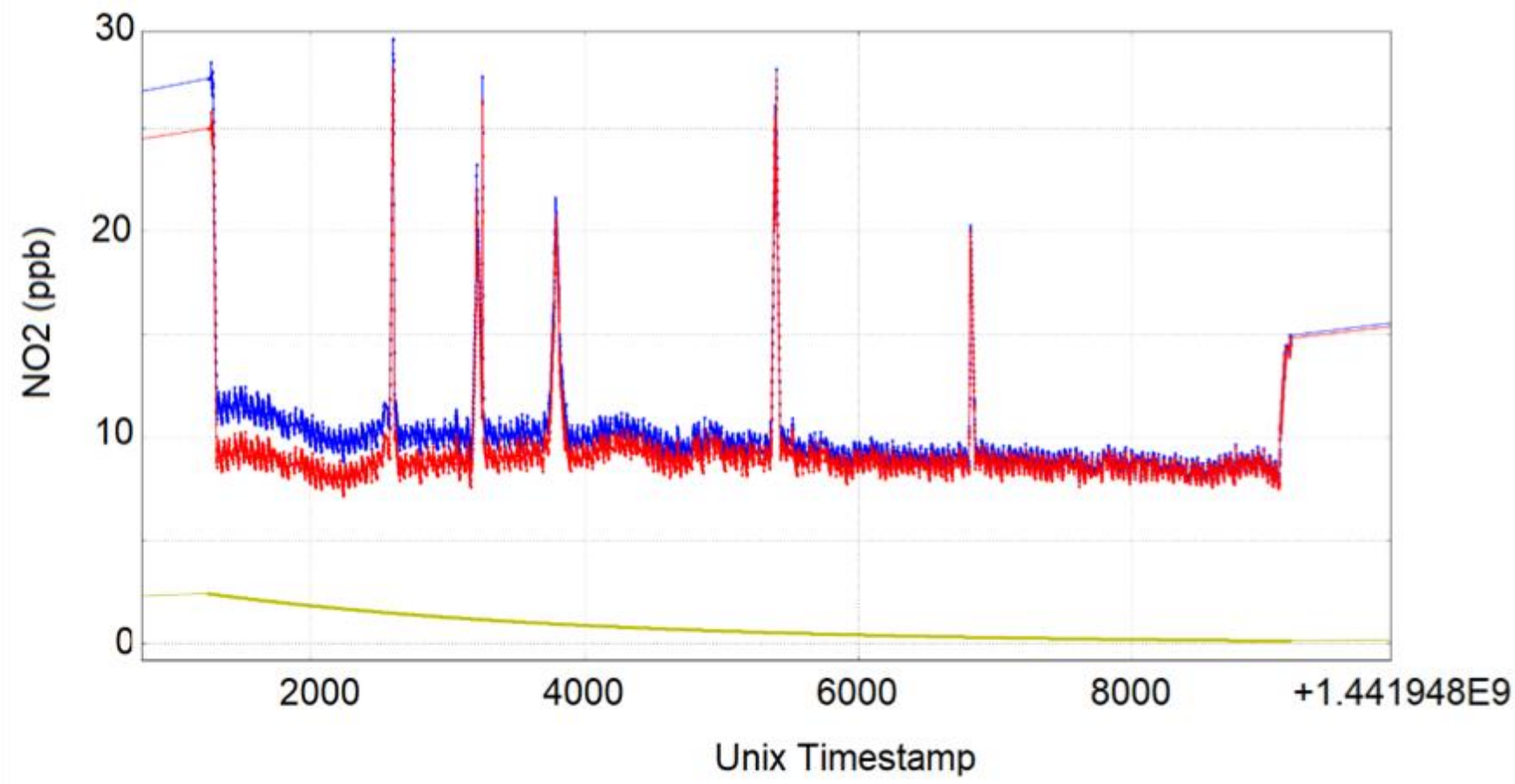

Figure 2 Corrected $\mathrm{NO}_{\mathrm{x}}$ signal using an exponentially decaying curve. The blue signal is the raw data, the red is the corrected data and the yellow is the exponential correction factor. 